\title{
Crescimento vegetativo e intensidade de cor verde das folhas de limeira ácida 'Tahiti' anelada e tratada com ácido giberélico
}

\author{
Vegetative growth and intensity of green color of the leaves of acid lime trees 'Tahiti' girdled and \\ treated with gibberellic acid
}

\author{
Cassiano Spaziani Pereira ${ }^{\mathrm{I}}$ Dalmo Lopes de Siqueira ${ }^{\mathrm{II}}$ Dierlei dos Santos ${ }^{\mathrm{I}}$ \\ Luiz Carlos Chamum Salomão ${ }^{\text {II }}$ Paulo Roberto Cecon ${ }^{\mathrm{III}}$
}

\section{RESUMO}

\begin{abstract}
Neste trabalho, o objetivo foi avaliar se o anelamento de ramos reduz o crescimento vegetativo em limeiras ácidas 'Tahiti' e se a aplicação de $A_{3}$ é capaz de recuperá-lo. $O$ delineamento utilizado foi em blocos casualizados, em esquema fatorial, com cinco repetições. $O$ primeiro fator consistiu na aplicação foliar de quatro concentrações de $\mathrm{AG}_{3}\left(0,7,14\right.$ e $\left.21 \mathrm{mg} \mathrm{L}^{-1}\right)$, quando cerca de $80 \%$ das pétalas haviam sofrido abscisão. O segundo fator referiu-se aos tratamentos sem anelamento, anelamento no início do florescimento e anelamento um mês após o florescimento. As variáveis analisadas foram altura das plantas, comprimento dos ramos, diâmetro e volume das copas, e intensidade de cor verde das folhas. A aplicação de $A G_{3}$ não causou efeito sobre o crescimento vegetativo e intensidade de cor verde das folhas. $O$ anelamento de ramos, independentemente da época em que foi realizado, retardou o crescimento vegetativo das plantas e reduziu a intensidade de cor verde das folhas da limeira ácida 'Tahiti'; porém, na última avaliação, não foram verificadas diferenças significativas em relação às plantas sem anelamento.
\end{abstract}

Palavras-chave: Citrus latifolia Tan., anelamento, $A G_{3}$, índice SPAD.

\section{ABSTRACT}

The objective was to assess whether the girdling reduces the vegetative growth in acid lime 'Tahiti' and the application of $\mathrm{GA}_{3}$ is able to retrieve it. The design was a randomized block design, in factorial with five replications. The first factor consisted of four concentrations of foliar application of $\mathrm{GA}_{3}\left(0,7,14\right.$ and $\left.21 \mathrm{mg} \mathrm{L}^{-1}\right)$ when about $80 \%$ of the petals had abscised. The second factor referred to the treatments without girdling, girdling at flowering, and girdling a month after flowering. The variables were plant height, branch length, diameter and canopy volume, and intensity of green color of the leaves. The application of $\mathrm{GA}_{3}$ had no effect on vegetative growth and intensity of green color of leaves. Girdling, regardless of the time it was done, delayed vegetative growth of plants and reduced the intensity of green color of the leaves of acid lime 'Tahiti' tree, but in the last evaluation there was no statistically significant differences regarding the plants without girdling.

Key words: Citrus latifolia Tan., girdling, $A G_{3}$, SPAD index.

\section{INTRODUÇÃO}

O anelamento de ramos é uma técnica utilizada em várias espécies frutíferas com objetivos de manipular a florada, fixar frutos e antecipar a colheita. Consiste na retirada de um anel completo da casca (epiderme, capas subepidérmicas e floema) do tronco ou dos ramos da planta, interrompendo o transporte via floema e favorecendo o acúmulo de carboidratos nas folhas acima da região anelada, enquanto os frutos (drenos) os reduzem (COHEN, 1981; SARTORI \& ILHA, 2005). Aumentando-se a disponibilidade de carboidratos na copa das plantas, reduz-se a competição entre crescimento vegetativo e reprodutivo ou mesmo entre frutos, resultando em aumentos consideráveis no pegamento e, consequentemente, na produção (COHEN, 1981).

'Departamento de Fitotecnia, Universidade Federal de Rondônia (UNIR), Rolim de Moura, RO, Brasil.

"Departamento de Fitotecnia (DFT), Universidade Federal de Viçosa (UFV), 36570-000, Viçosa, MG, Brasil. E-mail: dierlei@vicosa.ufv.br. Autor para correspondência.

IIIDepartamento de Estatística, UFV, Viçosa, MG, Brasil. 
Dependendo da época em que é realizado, o anelamento estimula a floração(PÉREZ \& RODRIGUEZ, 1987), aumenta a fixação de frutos (AGUSTÍ et al., 1996; AGUSTÍ, 1999), aumenta o tamanho e melhora características de qualidade como cor, teor de açúcares e acidez (AGUSTÍ et al., 1996), podendo também antecipar a maturação (SARTORI et al., 2003).

Apesar dos efeitos benéficos do anelamento, inúmeros efeitos indesejáveis podem ocorrer, como redução do porte das plantas, diminuição da taxa fotossintética e amarelecimento das folhas (FACHINELLO, 1986). Esses efeitos podem ocorrer devido a três motivos: acúmulo de carboidratos, principalmente amido, nos cloroplastos, que inibe a taxa fotossintética das plantas, sendo esse fenômeno conhecido como retroinibição (IGLESIAS et al., 2002); redução no crescimento das raízes, que reduz a absorção de nutrientes pelas plantas (FACHINELLO, 1986); e aumento na concorrência por fotoassimilados, entre parte vegetativa e reprodutiva, devido ao aumento no pegamento de frutos que essa prática propicia (MATAA et al., 1998).

As giberelinas $\left(\mathrm{AG}_{3}\right)$ são substâncias que atuam principalmente na mobilização de reservas no endosperma, na germinação das sementes, no alongamento de brotos (crescimento das plantas), no desenvolvimento floral e na fixação de frutos (TAIZ \& ZEIGER, 2004). A diminuição nas concentrações endógenas de giberelinas nos tecidos vegetais provoca redução no alongamento e na divisão celular e, consequentemente, redução no crescimento dos ápices vegetativos. Assim, aplicações exógenas de $\mathrm{AG}_{3}$, frequentemente, são eficazes para a superação da dormência e permitem que as plantas retomem seu crescimento (HUTTLY \& PHILLIPS, 1995). São recomendadas aplicações em citros com objetivo de recuperar o vigor de plantas depauperadas devido ao ataque de pragas, com anomalias fisiológicas ou quando é característica varietal florações elevadas que praticamente anulam brotações vegetativas ou mistas (CASTRO, 2001).

Desse modo, as giberelinas podem promover o crescimento vegetativo se aplicadas durante o repouso vegetativo ou início da brotação, inibindo o florescimento e aumentando a fixação de frutos conforme resumiu GRAVINA (2007). O tipo e a intensidade dessas respostas são dependentes da concentração aplicada, do estádio fenológico em que a planta se encontra no momento da aplicação e da variedade (KOSHITA et al., 1999; GRAVINA, 2007). Aplicações no período de indução floral geralmente reduzem o florescimento (KOSHITA et al., 1999; MAIA et al., 2010) e, durante a floração e queda das pétalas, promovem ou não a fixação de frutos. Se promoverem, há forte tendência em redução do tamanho final do fruto devido à concorrência por carboidratos (GRAVINA, 2007). Diante disso, o objetivo do trabalho foi avaliar se o anelamento de ramos reduz o crescimento vegetativo em limeiras ácidas 'Tahiti' e se a aplicação de $\mathrm{AG}_{3}$ é capaz de recuperá-lo.

\section{MATERIAL E MÉTODOS}

O experimento foi conduzido no Setor de Fruticultura da Universidade Federal de Viçosa (UFV), situado a $20^{\circ} 45^{\prime} 39^{\prime \prime}$ de latitude sul e $42^{\circ} 50^{\prime} 51^{\prime \prime}$ de longitude oeste, $650 \mathrm{~m}$ de altitude. O clima da região foi classificado, pelo sistema de Köeppen, como Cwamesotérmico úmido, com verões úmidos e invernos secos. A média anual das temperaturas máximas e mínimas é, respectivamente, de $26,1^{\circ} \mathrm{C}$ e $14,0^{\circ} \mathrm{C}$, a pluviosidade anual é de $1.340 \mathrm{~mm}$, e a média anual da umidade relativaé de $80 \%$ (VIANELLO \& ALVES, 2006).

Foram utilizadas plantas de limeira ácida 'Tahiti' (Citrus latifolia Tanaka) com oito anos de idade, enxertadas em limoeiro 'Cravo' (Citrus limonia Osbeck) e conduzidas sem irrigação. O período de condução do experimento foi de 18/08/2006, início do florescimento, até a última colheita dos frutos, no final de abril de 2007. O delineamento utilizado foi em blocos casualizados (DBC), em esquema fatorial, com cinco repetições e duas plantas por parcela. $O$ primeiro fator consistiu na aplicação foliar de quatro concentrações de AG (0, 7, 14 e 21 $\left.\mathrm{mg} \mathrm{L}^{-1}\right)$ em 13/09/2006. O segundo fator rẻferiu-se aos tratamentos sem anelamento (SA), anelamento no início do florescimento (AIF), em 21/8/ 2006, e anelamento um mês após o florescimento (AMAF), em 21/9/2006. As soluções de $\mathrm{AG}_{3}$ foram preparadas no mesmo dia da aplicação, sendo adicionado espalhante adesivo siliconado. A aplicação foi feita utilizando-se pulverizador manual, quando cerca de $80 \%$ das pétalas haviam sofrido abscisão (PRIMO-MILLO, 1993).

$\mathrm{O}$ anelamento foi feito a aproximadamente $15 \mathrm{~cm}$ acima do local da enxertia. Removeu-se uma porção da casca de $5 \mathrm{~mm}$ de espessura, com auxílio de um canivete com lâminas duplas, que permitiu uniformidade dos cortes. Durante a operação, tomouse cuidado de não aprofundar demasiadamente o corte para não danificar o xilema de forma a não interromper o fluxo ascendente de água e nutrientes para a região acima do anelamento (SARTORI et al., 2003).

As características avaliadas foram: altura de planta, diâmetro e volume de copa, comprimento de ramos floríferos e intensidade de cor verde das folhas (índice SPAD). A altura das plantas foi avaliada 
mensalmente, de agosto de 2006 (início do experimento) a abril de 2007 (final da colheita dos frutos), totalizando sete avaliações, sendo medido do colo até o ápice, com auxílio de trena e escada. O diâmetro da copa e o comprimento dos ramos foram avaliados apenas uma vez, no dia 4/1/2007, quando havia ocorrido a maturação do segundo fluxo de brotação após o florescimento. $\mathrm{O}$ volume foi determinado pela equação proposta por AULER et al. (2008), para cálculo de volume de copa de citros, sendo: volume de copa $=2 / 3 * \mathrm{p} * \mathrm{R} 2 * \mathrm{H}$, em que $\mathrm{R}$ é o raio da copa, e Hé a altura da planta medida do início da sua copa até o ápice, desconsiderando a altura do tronco. Para avaliação do comprimento dos ramos, foram selecionados quatro em cada planta dispostos em diagonal, sendo medido seu comprimento com auxílio de trena. Considerou-se como base o fluxo de crescimento ocorrido na primavera.

As determinações da intensidade de cor verde das folhas (índice SPAD) foram efetuadas mensalmente, de agosto de 2006 até abril de 2007, sendo amostradas seis folhas maduras por planta, 12 por parcela, localizadas na parte mediana das plantas, em ramos imediatamente abaixo dos ramos do último fluxo de crescimento. Foi utilizado o medidor portátil de clorofila SPAD-502 (Soil-Plant Analysis Development).

Para as características altura de planta e índice SPAD, o esquema utilizado foi em parcelas subdivididas no tempo, com o fatorial $4 \times 3$ nas parcelas e o tempo de avaliação $(0,30,60,90,120,150,180$ e 210 dias após o florescimento) nas subparcelas. Quanto às características diâmetro e volume de copas, e comprimento dos ramos, foi utilizado o esquema fatorial $4 \times 3$. Os dados obtidos foram submetidos à análise de variância e de regressão. Para o fator qualitativo (anelamento), as médias foram comparadas utilizandose o teste de Tukey, a 5\% de probabilidade. Quanto ao fator quantitativo (doses de $\mathrm{AG}_{3}$ ), os modelos foram escolhidos com base na significância dos coeficientes de regressão, sendo utilizado o teste "t", $5 \%$ de probabilidade de determinação, no valor do $\mathrm{r}^{2}$ e no potencial para explicar o fenômeno biológico.

\section{RESULTADOS E DISCUSSÃO}

A aplicação de $\mathrm{AG}_{3}$ não causou efeito na altura das plantas, no comprimento de ramos, no diâmetro e no volume de copa e na intensidade de cor verde das folhas em limeira ácida 'Tahiti'. Esses resultados são similares aos observados em outras pesquisas com citros, as quais não verificaram alteração nas características vegetativas das plantas em concentrações que variaram de 20 a $75 \mathrm{mg} \mathrm{L}^{-1}$ (LEONEL \& RODRIGUES, 1996; SANCHES et al., 2001;
SERCILOTO et al., 2003; MAIA, et al., 2010), demonstrando que a ausência de resposta possivelmente não seja devido a doses usadas. Segundo POWELL (1987), para obtenção de aumento no tamanho das plantas, há necessidade de aplicações constantes de $\mathrm{AG}_{3}$ para a maioria das espécies, já que uma única aplicação nem sempre é suficiente para obtenção de bons resultados. Além disso, há relatos na literatura que demonstram que os resultados com aplicação de $\mathrm{AG}_{3}$ são pontuais, ou seja, existe um momento específico de aplicação para que a resposta ocorra e é altamente dependente de condições ambientais. Como foi realizada apenas uma aplicação, é possível que o momento não tenha sido o mais adequado (CASTRO, 2001; SERCILOTO \& CASTRO, 2001).

SERCILOTO et al. (2003) observaram que a aplicação de $20 \mathrm{mg} \mathrm{L}^{-1}$ de $\mathrm{AG}_{3}$ foi suficiente para elevar em 9\% o índice SPAD nas folhas de 'Tahiti' e atribuíram ao aumento na assimilação de $\mathrm{CO}_{2}$ esse incremento de clorofila e a maior fixação de frutos, que, entretanto, não proporcionou alteração no crescimento vegetativo das plantas, resultado semelhante ao observado neste trabalho. As maiores taxas de assimilação de $\mathrm{CO}_{2}$, em resposta à aplicação de $\mathrm{AG}_{3}$, se devem a uma ação direta dos biorreguladores nos componentes do aparelho fotossintético ou no efeito indireto devido ao aumento na força de dreno gerada pela maior fixação de frutos.

Em relação ao tratamento baseado no anelamento dos ramos, verificou-se que, independentemente da época em que foi realizada, essa técnica retardou o crescimento vegetativo das plantas e reduziu a intensidade de cor verde das folhas de 'Tahiti' (Tabelas 1, 2 e 3). Observou-se retardamento no crescimento das plantas aneladas no período entre

Tabela 1 - Altura das plantas (m) de limeira ácida 'Tahiti' sem anelamento (SA), com anelamento no início do florescimento (AIF) e anelamento um mês após o florescimento (AMAF), no período entre 90 dias após $\mathrm{o}$ início do florescimento e a colheita.

\begin{tabular}{lccccc}
\hline $\begin{array}{l}\text { Época de } \\
\text { anelamento }\end{array}$ & 90 & 120 & 150 & 180 & 210 \\
\hline AS & $2,1 \mathrm{a}$ & $2,2 \mathrm{a}$ & $2,3 \mathrm{a}$ & $2,5 \mathrm{a}$ & $2,5 \mathrm{a}$ \\
$\mathrm{AIF}$ & $2,0 \mathrm{a}$ & $2,0 \mathrm{~b}$ & $2,1 \mathrm{c}$ & $2,3 \mathrm{c}$ & $2,5 \mathrm{a}$ \\
$\mathrm{AMAF}$ & $2,0 \mathrm{a}$ & $2,1 \mathrm{ab}$ & $2,2 \mathrm{~b}$ & $2,4 \mathrm{~b}$ & $2,5 \mathrm{a}$ \\
& & & & & \\
$\mathrm{CV} \mathrm{a}(\%)=12,0$ & & & & \\
$\mathrm{CV} \mathrm{b}(\%)=4,0$
\end{tabular}

Médias seguidas das mesmas letras, nas colunas, não diferem entre si a 5\% de probabilidade pelo teste de Tukey. 
Tabela 2 - Comprimento de ramos (CR), diâmetro de copas (DC) e volume de copas (VC) de plantas de limeira ácida 'Tahiti' sem anelamento (SA), com anelamento no início do florescimento (AIF) e anelamento um mês após o florescimento (AMAF), 150 dias após o início do florescimento.

\begin{tabular}{llll}
\hline $\begin{array}{l}\text { Época de } \\
\text { anelamento }\end{array}$ & CR $(\mathrm{cm})$ & $\mathrm{DC}(\mathrm{m})$ & $\mathrm{VC}\left(\mathrm{m}^{3}\right)$ \\
\hline $\mathrm{AS}$ & $22,8 \mathrm{a}$ & $1,8 \mathrm{a}$ & $3,4 \mathrm{a}$ \\
$\mathrm{AIF}$ & $17,9 \mathrm{~b}$ & $1,6 \mathrm{~b}$ & $2,4 \mathrm{~b}$ \\
$\mathrm{AMAF}$ & $19,6 \mathrm{~b}$ & $1,7 \mathrm{ab}$ & $2,8 \mathrm{~b}$ \\
$\mathrm{CV}(\%)$ & 18,6 & 9,3 & 22,9 \\
\hline
\end{tabular}

Médias seguidas das mesmas letras, nas colunas, não diferem entre si a $5 \%$ de probabilidade pelo teste de Tukey.

120 e 180 dias após o florescimento. A partir de 210 dias, com a recuperação dos tecidos da região anelada, houve restabelecimento do crescimento dessas plantas, cuja altura final se igualou ao crescimento das plantas testemunhas (AS) (Tabela 1). As maiores diferenças observadas na altura das plantas, proporcionadas pelo anelamento, ocorreram entre 150 e 180 dias após o início do florescimento. Aos 150 dias, houve redução de 9 e $4 \%$, e aos 180 dias essa redução foi de 8 e $4 \%$ nas plantas com AIF e AMAF, respectivamente, em relação às plantas SA (Tabela 1). As plantas com AIF apresentaram menor comprimento de ramos, diâmetro e volume de copa, com redução de 21,11 e $29 \%$, respectivamente, em relação às plantas SA. Nas plantas com AMAF, essa redução foi de 14, 6 e 18\%, respectivamente, em relação às plantas $\mathrm{SA}$ (Tabela 2).

$\mathrm{O}$ anelamento de ramos promoveu amarelecimento nas folhas das plantas, com consequente redução do índice SPAD. Naquelas que receberam AIF, essa redução ocorreu entre 60 e 180 dias após o tratamento, e entre 120 e 180 dias naquelas que receberam AMAF. Esse amarelecimento na folha é um dos motivos preocupantes da adoção do anelamento como prática rotineira, pois significa redução na concentração de nitrogênio foliar, que pode contribuir para a redução da capacidade fotossintética a longo prazo, uma vez que onitrogênioé integrante da molécula de clorofila (URBAN \& ALPHONSOUT, 2007). A maior redução do índice SPAD foi verificada naquelas com AIF e ocorreu aos 120 dias após o florescimento, correspondendo a 12,3 unidades SPAD ou 19\% em relação às plantas SA. Nas plantas com AMAF, a maior redução também foi observada aos 120 dias após o florescimento, mas de menor intensidade do que a verificada nas plantas com o AIF, sendo de 7,3 unidades SPAD ou $11 \%$ em relação às plantas SA (Tabela 3 ). Ao final do experimento, 210 dias após o início do florescimento e com a recuperação dos tecidos da região anelada, as folhas tanto das plantas com AIF, quanto daquelas com AMAF, apresentaram intensidade de cor verde normal, estatisticamente semelhante à das plantas SA (Tabela 3).

Os resultados obtidos com anelamento em plantas de citros estão de acordo com os obtidos por outros autores, que também observaram retardamento no crescimento vegetativo em plantas de pêssegos e nectarinas submetidas a essa prática (DANN et al., 1984; PÉREZ \& RODRIGUEZ, 1987). Essa redução no crescimento vegetativo ocorre porque o anelamento promove possivelmente o aumento na fixação de frutos, variável não avaliada neste estudo, e com isso há aumento da concorrência entre partes vegetativas e reprodutivas por fotoassimilados e, indiretamente, redução no tamanho dos ramos e até mesmo no diâmetro dos frutos (CUTTING \& LYNE, 1993).

O anelamento, ao impedir o fluxo de carboidratos solúveis da parte aérea para as raízes, promove aumento nos teores de carboidratos nas folhas (MATAA et al., 1998). Por outro lado, reduz os teores de açúcares solúveis e amido nas raízes (SIQUEIRA et al., 2004; LI et al., 2003), causando redução no crescimento e aumento na morte de raízes.

Tabela 3 - Índice SPAD nas folhas maduras de limeira ácida 'Tahiti' sem anelamento (SA), com anelamento no início do florescimento (AIF) e anelamento um mês após o florescimento (AMAF), no período de 30 até 210 dias após o florescimento.

\begin{tabular}{|c|c|c|c|c|c|c|c|}
\hline \multirow{2}{*}{$\begin{array}{l}\text { Época de } \\
\text { anelamento }\end{array}$} & \multicolumn{7}{|c|}{  } \\
\hline & 30 & 60 & 90 & 120 & 150 & 180 & 210 \\
\hline AS & $66,0 \mathrm{a}$ & $64,6 \mathrm{a}$ & $66,2 \mathrm{a}$ & $66,3 \mathrm{a}$ & $69,7 \mathrm{a}$ & $69,3 \mathrm{a}$ & $65,2 \mathrm{a}$ \\
\hline AIF & $62,1 \mathrm{a}$ & $59,6 \mathrm{~b}$ & $55,8 \mathrm{~b}$ & $54,0 \mathrm{c}$ & $60,4 \mathrm{~b}$ & $60,4 \mathrm{~b}$ & $63,3 \mathrm{a}$ \\
\hline AMAF & $62,1 \mathrm{a}$ & $63,3 \mathrm{ab}$ & $66,2 \mathrm{a}$ & $59,0 \mathrm{~b}$ & $63,6 \mathrm{~b}$ & $63,6 \mathrm{~b}$ & $62,2 \mathrm{a}$ \\
\hline \multicolumn{8}{|c|}{$\begin{array}{l}\mathrm{CV} \text { a }(\%)=13,3 \\
\mathrm{CV}(\%)=72\end{array}$} \\
\hline
\end{tabular}

Médias seguidas das mesmas letras, nas colunas, não diferem entre si a 5\% de probabilidade pelo teste de Tukey.

Ciência Rural, v.40, n.9, set, 2010. 
Por isso, há redução na absorção dos nutrientes minerais e na produção de giberelinas, resultando no amarelecimento das folhas e na redução do crescimento das plantas (FACHINELLO, 1986). O amido é o carboidrato que mais se acumula nas folhas, em altas concentrações, após o anelamento (MATAA et al., 1998). A molécula de amido, por ser insolúvel em água e estar em forma de grânulos, em altas concentrações no cloroplasto, dificulta a difusão do $\mathrm{CO}_{2}$ e promove a degradação das membranas dos tilacoides e de moléculas de clorofila, reduzindo diretamente a taxa fotossintética, podendo haver, consequentemente, um amarelecimento das folhas (redução no índice SPAD) e a redução na produção de fotoassimilados (COHEN, 1981; IGLESIAS et al., 2002). Reduções nas taxas fotossintéticas em plantas de citros submetidas ao anelamento foram relatadas por diversos autores e em outras cultivares (Citrus unshiu [Mak.] Marc. cv. 'Okitsu' (IGLESIAS et al., 2006), Citrus reticulata Hort. ex Tan. $\times$ Citrus paradisi Macf. $\times$ C. tangerina Hort. ex Tan cv 'Nova' e Citrus reticulata Blanco cv 'Loretina' (RIVAS et al., 2007).

A diferença na intensidade de efeito entre as duas épocas de anelamento sobre o crescimento vegetativo e a intensidade de cor verde das folhas pode ser devido ao crescimento de frutos, visto que o acúmulo de carboidratos nas plantas que receberam AMAF é por um menor período do que aquelas que receberam AIF. Sugere-se que o AMAF foi realizado quando os frutos iniciavam demanda crescente de carboidratos (final da fase I) (DAVIES \& ALBRIGO, 1994), minimizando os efeitos prejudiciais pelo acúmulo de amido, por longos períodos.

\section{CONCLUSÃO}

O anelamento de ramos, independentemente da época em que foi realizado, retardou o crescimento vegetativo das plantas e reduziu a intensidade de cor verde das folhas da limeira ácida 'Tahiti'. A aplicação de $\mathrm{AG}_{3}$ isoladamente não causou efeito sobre essas variáveis e, quando aplicado em plantas aneladas, não foi capaz de evitar os efeitos na redução do crescimento vegetativo, provocados pelo anelamento.

\section{REFERÊNCIAS}

AGUSTÍ, M. et al. Tratamientos para aumentar el tamaño del fruto en los agrios: Generalitat Valenciana. Valencia: Conselleria d'Agricultura i Pesca, 1996. 79p.

AGUSTÍ, M. Floración y fructificación de los cítricos. In: SIMPÓSIO INTERNACIONAL DE FRUTICULTURA, 1999, Botucatu. Anais... Botucatu: UNESP, 1999. p.161-185.
AULER, P.A.M. et al. Comportamento da laranjeira 'Valência' sobre seis porta-enxertos no noroeste do Paraná. Revista Brasileira de Fruticultura, v.30, p.229-234, 2008. Disponível em: 〈http://www.scielo.br/pdf/rbf/v30n1/42.pdf >. Acesso em: 27 maio, 2010. doi: 10.1590/S0100-29452008000100042.

CASTRO, P.R.C. Biorreguladores em citros. Laranja, v.22, p.367-381, 2001.

COHEN, A. Recent developments in girdling of citrus tree. Proceedings of the International Society of Citriculture, v.1, p.196-199, 1981.

CUTTING, J.G.M.; LYNE, M.C. Girdling and the reduction in shoot xylem sap concentrations of cytokinins and gibberellins in peach. Journal of Horticultural Science, v.68, p.619$626,1993$.

DANN, I.R. et al. Effects of limb girdling on growth and development of competing fruit and vegetative tissues of peach trees. Australian Journal of Plant Physiology, v.11, p.4958, 1984. Disponível em: <http://www.publish.csiro.au/paper/ PP9840049.htm>. Acesso em: 27 maio, 2010. doi: 10.1071/ PP9840049.

DAVIES, F.S.; ALBRIGO, L.G. Citrus. Wallingford: CAB International, 1994. 254p.

FACHINELlO, J.C. Efeitos morfo-fisiológicos do anelamento no enraizamento de estacas lenhosas de macieira cultivar Malling - Merton. 1986. 106f. Tese (Doutorado em Solos e Nutrição de Plantas) - Escola Superior de Agricultura "Luiz de Queiroz", SP.

GRAVINA, A. Aplicación del ácido giberélico en citrus: revisión de resultados experimentales en Uruguay. Agrociencia, v.11, p.57-66, 2007.

HUTTLY, A.K.; PHILLIPS, A.L. Gibberellin regulated plant genes. Physiologia Plantarum, v.95, p.310-317, 1995.

IGLESIAS, D.J. et al. Regulation of photosynthesis through source: sink imbalance in citrus is mediated by carbohydrate content in leaves. Physiologia Plantarum, v.116, p.563572, 2002. Disponível em: <http://www3.interscience.wiley.com/ cgi-bin/fulltext/118911655/PDFSTART >. Acesso em: 27 maio, 2010. doi: 10.1034/j.1399-3054.2002.1160416.x.

IGLESIAS, D.J. et al. Carbohydrate and ethylene levels related to fruitlet drop through abscission zone A in citrus. Trees, v.20, p.348-355, 2006. Disponível em: <http://www.springerlink.com/ content/f561860767h632r6/fulltext.pdf>. Acesso em: 13 jun. 2010. doi:10.1007/s00468-005-047-x.

KOSHITA, Y. et al. Involvement of endogenous plant hormones (IAA, ABA, GAs) in leaves and flower bud formation of Satsuma mandarin (Citrus unshiu Marc.). Scientia Horticulturae, v.79, p.185-194, 1999.

LEONEL, S.; RODRIGUES, J.D. Efeitos de giberelinas, citocininas e do nitrato de potássio no crescimento e desenvolvimento do porta-enxerto de limoeiro 'Cravo'. Scientia Agricola, v.53, p.261-266, 1996. Disponível em: <http:// www.scielo.br/scielo.php? script=sci_arttext\&pid=S010390161996000200012>. Acesso em: 13 jun. 2010. doi: 10.1590/ S0103-90161996000200012.

LI, C.Y. et al. Girdling affects carbohydrates - related gene expression in leaves bark and roots of alternate-bearing citrus 
trees. Annals of Botany, v.92, p.137-143, 2003. Disponível em: <http://aob. oxfordjournals.org/ci/reprint/92/1/137>. Acesso em: 27 maio, 2010. doi: 10.1093/aob/mcg108.

MAIA, E.F. et al. Produção, florescimento e frutificação de tangerineira 'Poncã' submetida à aplicação de ácido giberélico. Ciência Rural, v.40, p.507-512, 2010. Disponível em: <http:/ /www.scielo.br/pdf/cr/v40n3/a482cr1896.pdf>. Acesso em: 27 maio, 2010. doi: 10.1590/S0103-84782010005000025.

MATAA, M. et al. The effect of time of girdling on carbohydrate contents and fruiting in Ponkan mandarin (Citrus reticulata Blanco). Scientia Horticulturae, v.73, p.203211,1998

PÉREZ, B.H.; RODRIGUEZ, A.J. Efecto del anillado en el rendimiento y calidad del fruto de árboles de durazno (Prunus persica L.) bajo un sistema de producción intensiva. Agrociencia, v.68, p.63-73, 1987.

POWELL, L.E. The hormonal control of bud and seed dormancy in woody plants. In: DAVIES, P.J. (Ed.). Plant hormones and their role in plant growth and development. Dordrecht: Kluwer Academic, 1987. p.539-552.

PRIMO-MILLO, E. Regulación del cuajado del fruto en los cítricos. In: CONGRESO DE CITRICULTURA DE LA PLANA, 1993, Valencia. Anais... Nules: Ayuntamiento de Nules, 1993. p.57-74.

RIVAS, F. et al. Girdling effects on fruit set and quantum yield efficiency of PSII in two Citrus cultivars. Tree Physiology, v.27, p.527-535, 2007. Disponível em: <http:/ /treephys.Oxfordjournals.org/cgi/reprint/27/4/527>. Acesso em: 13 jun. 2010. doi: 10.1093/treephys/27.4.527.

SANCHES, F.R. et al. Efeito do ácido giberélico (AG ) na floração e produção da lima ácida 'Tahiti' (Citrus latifolia Tan.).
Revista Brasileira de Fruticultura, v.23, p.504-509, 2001. Disponível em: <http://www.scielo.br/pdf/rbf/v23n3/8013.pdf>. Acesso em: 08 jun. 2010. doi: 10.1590/S010029452001000300010 .

SARTORI, I.A. et al. Aplicação de auxinas e incisão anelar em pessegueiros da cv. Sentinela. Ciência Rural, v.33, n.2, p.247253, 2003. Disponível em: <http://www.scielo.br/pdf/cr/v33n2/ 15213.pdf>. Acesso em: 27 maio, 2010. doi: 10.1590/S010384782003000200011 .

SARTORI, I.A.; ILHA, L.L.H. Anelamento e incisão anelar em fruteiras de caroço. Ciência Rural, v.35, n.3, p.724-729, 2005. Disponível em: <http://www.scielo.br/pdf/cr/v35n3/ a40v35n3.pdf>. Acesso em: 11 jun. 2010. doi: 10.1590/S010384782005000300040 .

SERCILOTO, C.M. et al. Biorreguladores na fixação dos frutos da lima ácida 'Tahiti'. Laranja, v.24, p.383-395, 2003.

SIQUEIRA, D.L., et al. Florescimento de tangerinas satsuma 'Owari' tratadas com paclobutrazol, anelamento do caule e baixa temperatura. Revista Brasileira de Fruticultura, v.26, n.3, p.406-409, 2004. Disponível em: <http://www.scielo.br/pdf/ rbf/v26n3/23133.pdf >. Acesso em: 27 maio, 2010. doi: 10.1590/S0100-29452004000300009.

TAIZ. L; ZEIGER. E. Fisiologia vegetal. 3.ed. Porto Alegre: Artmed, 2004. 719p.

URBAN, L.; ALPHONSOUT, L. Girdling decreases photosynthetic electron fluxes and induces sustained photoprotection in mango leaves. Tree Physiology, v.27, p.345-352, 2007a. Disponível em: <http://treephys.oxfordjournals.org/cgi/reprint/27/3/345>. Acesso em: 13 jun. 2010. doi: 10.1093/treephys/27.3.345.

VIANELlo, R.L.; ALVES, A.R. Meteorologia básica e aplicações. 4.ed. Viçosa, MG: UFV, 2006. 449p. 